\title{
Innovative solutions for forming supply chains in the conditions of economic instability
}

\author{
Tatiana Kharlamova $^{1, *}$, Andrey Kharlamov ${ }^{2}$, and Peter Lemeshchenko ${ }^{3}$ \\ ${ }^{1}$ Peter the Great St. Petersburg Polytechnic University, 29, Polytechnicheskaya str., 195251, St. \\ Petersburg, Russia \\ ${ }^{2}$ St. Petersburg State University of Economics, 21, Sadovaya, 191023, St. Petersburg, Russia \\ ${ }^{3}$ Belarusian State University, 4, Nezavisimosti Avenue, 220030, Republic of Belarus
}

\begin{abstract}
The article examines the changes in the requirements for the development and implementation of innovations in the process of forming and improving supply chains in the face of increasing economic instability. Economic instability is presented as the most important trend in the modern economy and significant factor forming new requirements for supply chains. This, in turn, involves the improvement of applied technologies and development of new technologies, as well as the search for progressive technical and managerial solutions to meet the interests of a wide range of business entities and consumers of goods and services. A distinctive feature of this study is the fact that economic instability is viewed by the authors through the prism of both economic and non-economic processes having, inter alia, an impact on the economic system, including political, military, environmental, epidemiological and other processes. The article focuses on the COVID-19 coronavirus pandemic, as well as its impact on logistics solutions, and the specific demands on supply chains. It is substantiated that the introduction of technical and managerial innovations in this area will allow us to take into account the features and consequences of the impact of COVID-19 on the economy and to effectively influence the processes associated with improving supply chains. Thus, it will ensure compliance with the requirements and conditions determined by modern conditions associated with increased economic instability.
\end{abstract}

\section{Introduction}

Economic instability today should be considered as the fundamental process on the basis of which the work of any business structure is built and the global economy functions. And if at the beginning of the era of the market economy and further, over a long period of its evolution, instability was considered as a consequence of the cyclical nature of development (the rise was replaced by a decline) then at present, most researchers characterize instability as a much more complex process. This is due to the fact that economic instability in the modern period is increasingly becoming a consequence of processes and phenomena of a non-economic nature. Manifestations of instability can be provoked by the need to solve different political, ideological, military, environmental and other problems. Moreover, if

\footnotetext{
*Corresponding author: Kharlamova_t@list.ru
} 
these tasks themselves, as a rule, remain relevant for a fairly limited time, then decisions made on their basis can lead to economic instability in the medium and long term. According to existing forecasts, in the future this trend will only intensify, which presupposes the functioning of business entities in a new reality determined by economic instability. In our opinion, this is of particular importance in the process of forming supply chains - both economic resources for producers and finished products for consumers. Due to the fact that the modern market economy of the period of globalization, to a greater extent than before, uses specialization and integration between entrepreneurial structures located in different countries, the formation of effective supply chains aimed at stable work in the long term has great importance. It allows us to determine the goal of this article: to develop the main directions that provide effective logistics solutions and construction of sustainable supply chains in the conditions of economic instability. Since the factors of economic instability can be of both economic and non-economic nature, the formation of sustainable supply chains must take into account the political, military, environmental, epidemiological and other processes taking place today. Thus, the goal of this article is formulated in accordance with the current factors of instability, including the COVID-19 coronavirus pandemic, and is focused on meeting the interests of a wide range of business entities and consumers of goods and services.

\section{Materials and Methods}

When solving this problem, we should proceed from the fact that any entrepreneurial structure, dynamically developing, acquires an increasingly complex, ramified structure. This leads to the complication of economic ties and increasing requirements for the management process, including the determination of priorities and the main directions of development. Abstracting from the details, what is happening can be described by three key directions that determine the target orientation of the entrepreneurial structure:

- striving for maximum profit;

- the desire to develop the business and increase the level of competitiveness of the entrepreneurial structure;

- the desire to provide the sustainability and the effectiveness of economic ties and supply chains used by the company during the period of increasing economic instability.

In fact, these areas, one way or another, reflect the main stages of the life cycle of an entrepreneurial structure. The first of the presented directions is associated with the origin and initial functioning of the company, when its main tasks are survival and laying the foundation for future development. In this context, getting profit gives the company the opportunity to cover the starts costs of creating and finding a market niche. At the initial stages of the life cycle, the process of forming supply chains, both raw materials and produced products, is rather simplified and unstable, since the efforts of its participants are aimed at finding the best options, including by the "trial and error" method.

The second direction involves the search for development tools ensuring an increase in the scale of the company, a change in the assortment policy, the use of new technologies in production and management, as well as an increase in the level of competitiveness, both on the national and global markets [1]. It is obvious that an increase in the scale of a business creates new, additional requirements for the organization of supply chains, covering various components of the logistic sector and affecting the level of competitiveness of the company. As part of this, the growth of interest of entrepreneurs in the development and implementation of various innovations in the field of production and management is recorded [2,3]. This, in turn, expands the quantitative and qualitative characteristics of supply chains, introducing innovative content into logistic processes. 
The most significant requirements for innovative solutions arise in the implementation of the third direction, since ensuring the sustainability during a period of increasing economic instability becomes an essential condition for the effective functioning of a competitive company. The activity of entrepreneurial structures at the stages of the life cycle associated with ensuring the sustainability is becoming the most sensitive in relation to most of the processes occurring both at the local level and on the scale of the national and global economy. The processes that increase global instability (especially of non-economic origin) today have an increasingly noticeable impact on ensuring the sustainability of supply chains, as well as the possibility of their rapid and effective transformation. At the same time, the use of innovative solutions comes to the fore, especially if supply chains and economic ties in a short-term period change significantly, or even break down $[4,5]$. Innovation needs to encompass both supply chain organization and supply chain management, ensuring synergies in an environment of economic instability.

In today's conditions, the stability of economic relations depends, among other things, on the number of participants in the supply chains, which, as a rule, is growing now. This trend is due to the widespread introduction of innovations and the specialization of entrepreneurial structures in specific types of business activities. As for Russia, as the performed analysis shows, there are multidirectional trends in the processes affecting the efficiency of supply chains, including negative ones. Considering the nature of logistic processes in the domestic economy in the modern period (two decades of the XXI century), the following dynamics can be identified:

- In 1 the period from 2000 to 2008, the Russian economy demonstrated rapid economic growth, the annual rates of which often exceeded $7 \%$, which was reflected in the acceleration of business activity and entrepreneurial initiative. During this period, there was the multiplication of the number of entrepreneurial structures, the growth of the income of the population, an increase in the volume of demand for various goods, both for industrial and consumer purposes, as well as in the volume of economic resources. The relations with foreign companies that supply goods to the Russian market and invest in the creation of production facilities in Russia were actively expanding. This can be illustrated by a multitude of examples related to the production of cars, pharmaceuticals, food products, household appliances, etc. In addition, during the period under review, foreign representative offices of Russian firms, as well as domestic companies that supplied goods to the foreign market were actively developing. Against this background, the innovative content of supply chains increased, which became more diverse, complex and, at the same time, significantly dependent on foreign players (including logistics companies).

- Between 2009 and 2016, there was a significant drop in the volume of supply chains, as well as the destruction of some of them. The beginning of this process is associated with the global economic crisis of 2008-2009; its continuation was the result of the introduction of a package of economic sanctions against our country as a whole and individual business structures. An active period of sanctions pressure began in 2014 (if we consider in more detail the impact of sanctions on the Russian economy, it should be noted that first they were introduced in 2013 by the United States. Before that, in 2010-2012, there were some restrictions against individuals, engaged in entrepreneurial activity). In general, currently there are sanctions against 36 Russian transport companies [6]. Of course, it would be inaccurate to examine the impact of sanctions only on transport companies when considering changes in supply chains. Definitely, the sanctions negatively affected the activities of firms operating in various areas of entrepreneurial activity, up to the introduction of a complete interdiction on the supply of certain types of goods. This led not only to the suspension, but also, in some cases, to the destruction of supply chains, worked in the framework of mutually beneficial cooperation for decades [7]. It should be recognized that the retaliatory measures 
of the Russian government - the imposed counter-sanctions - have further intensified these negative processes.

As a part of the characteristics of this stage, it should be emphasized that not only destruction took place here, but also creation, which manifested in the search for new supply chains. In essence, this has led to a re-division of the market based on new priority requirements: safety and sustainability. During this period (especially in its final part), the growth of Russian logistics companies took place when they were organizing supply chains to ensure the protection of Russian business from possible intensification of sanctions with maximum self-reliance, combined with active promotion to foreign markets.

- The period that began in 2017 , with its specific dynamics, continues to this day. It is characterized not only by the further development of supply chains within the country, but also by the expansion of the capabilities of Russian logistics companies when working with foreign partners. In general (with certain reservations) we can say that the development of internal supply chains was the result of the adaptation of Russian business structures to the sanctions imposed against our country.

The COVID-19 coronavirus pandemic, which determined the functioning of all areas of the socio-economic system in 2020 , should also be considered as a factor of instability of a non-economic nature, which has transformed the most of the logistic decisions of the current period. The restrictions associated with the spread of the coronavirus required strengthening supply chains and increasing their reliability, as well as the rapid introduction of digital technologies at all stages of functioning of economic ties. The pandemic has revealed new market segments that were previously unclaimed due to little demand or lack of convenience for consumers. We are talking about the explosive growth of supply chains serving individual or corporate customers interested in small lots of goods, as well as individual entrepreneurs who need economic resources to support the production process. Another distinctive feature of today is the need to minimize personal contacts during the delivery process. All this requires the development and implementation of innovative solutions in organizing supply chains $[8,9,10]$ in the context of growing processes of economic instability.

In the context of these requirements, a number of the most important innovative solutions can be proposed:

1. Acceleration of all processes and operations in the delivery of goods to consumers

In the context of increasing economic instability, this provision is of particular importance, since in a period of rapid changes in the market, large time intervals between sending and receiving goods can make the entire delivery process meaningless [11]. Based on this, it is necessary to constantly improve the process of supply chain management in real time, taking into account the dynamically changing conditions. The modern process of division and specialization against the background of the development of digital technologies leads to the creation and use of huge amounts of data, the users of which are numerous business entities and individual consumers. In these conditions, the effective functioning of logistics companies presupposes the expansion of the use of big data as a tool for working with heterogeneous structured and unstructured information.

Modern requirements in the field of the delivery mode in real time (SCV) cannot be realized without constant improvement of the applied information technologies [12]. An analysis of existing practice indicates the rapid growth of this area in 2019, preceding the COVID-19 coronavirus pandemic. During the pandemic, the digital systems helped to cope with the avalanche-like growth in demand for the delivery of goods, mainly from retail consumers, in the face of a sharp decrease in internal and external transport flows.

2. Using advanced analytics based on data standardization

This innovative solution is aimed at overcoming the existing difficulties associated with historical practices. Traditionally, many companies involved in the development and implementation of supply chains store their data in the most convenient form for them and 
use certain software. Often, when the companies are carrying out any joint work with other participators, their data turns out to be incompatible. Similar restrictions reduce the efficiency of the processes being implemented, and simply contradict the requirements of our time. Based on this, the development of standards in the field of digitalization that could be used by all logistics companies operating in a particular area comes to the fore. Such developments are being actively carried out and implemented today; however, this process needs to be intensified. We believe that the related niche can be successfully occupied by independent startups specializing in software development. Not being dependent on specific logistics companies, they will be able to avoid the temptation of using traditional standardization systems that are already in use and offer new, advanced software systems.

3. Application of blockchain technologies

The use of this technology can significantly improve the efficiency of management decisions in almost all areas of the economy, including supply chain management. Blockchain is a complex algorithm, the main advantage of which is due to the new level of interaction between business entities. When using blockchain, all participants in the supply chain - customers, performers, intermediaries - use a simplified interaction mechanism, and at the same time receive a guarantee of protection against penetration of third parties [13]. This is especially important in the exchange of commercial information, as well as in the execution of contracts and their payment. With all the complexity of blockchain technology, today it is rapidly spreading throughout the world. Its colossal prospects in optimizing the processes of organizing and implementing supply chains, as well as ensuring the safety of their participants [14], fully meet the requirements of working in conditions of economic instability.

4. Increased use of Internet of Things (IoT) technology

As applied to the organization of supply chains, this technology helps to track the movement of goods in real time at all links of the chain and all time periods. However, from a managerial standpoint, we should look at the IoT technology more broadly. This technology allows us to analyze the existing supply chains and identify areas where the greatest time and money costs are recorded (when moving, handling and sorting goods, as well as in the process of equipment maintenance and repair). Obtaining such information gives entrepreneurial structures an effective tool for finding the most appropriate solutions when optimizing delivery processes by the criterion of time and costs. [15].

5. Improving the modeling process and giving it advanced functions

In formulating this proposal, we proceed from the fact that when practically any computer model is implemented in practice, the resulting original will always differ from the prototype $[16,17,18]$. This is due not so much to errors or flaws in the model as to the presence of hard-to-predict deviations in the process of its development and use. Often, at the modeling stage, it is difficult to take into account all the changes that will be made in the future to the developed supply chain model, as well as the nature and degree of wear and tear of machinery and equipment. The problems arising in this case could be solved by the use of modern Digital Twin technology. Its application opens up great opportunities for analyzing logistic processes and developing detailed programs for maintenance, repair and replacement of equipment involved in the implementation of supply chains.

The use of Digital Twin technology is characterized today as a breakthrough innovative solution that allows us to receive and process huge amounts of disparate data reflecting the movement of goods, wear of containers and packaging, rhythm of delivery times, etc. The result of the application of this technology is the identification of trends and patterns that ensure the improvement of supply chains, as well as forecasting the actions of companies in the strategic perspective.

6. Application of artificial and augmented intelligence 
The importance of introducing artificial and augmented intelligence today is not questioned by anyone. With regard to logistic solutions, this allows entrepreneurs to develop and implement so-called intelligent transportation with clearly calculated routes and specified time parameters for the beginning and end of the movement of goods. In the modern conditions of economic instability, the role of augmented intelligence, which provides an optimal combination of the capabilities of human and computer intelligence, increases many times over. It can be predicted that in the future, the share of human intervention in the process of organizing supply chains will gradually decrease, and artificial intelligence will increase $[19,20,21,22]$. At the same time, computers will take over most of the operations in the planning and development of supply chains and transportation parameters, as well as analyzing the prospects for the formation of demand for transportation. Thus, the management of modern companies will receive a formed basis for making balanced and rational managerial decisions of a strategic nature.

7. Widespread use of robotics

The implementation of this solution leads to significant changes in the organization of logistic processes, especially in the work of warehouses. The widespread introduction of robotics makes it possible not only to cut a number of employees for optimizing staff, but also, more importantly, to reduce possible errors and violations during warehousing and to speed up the processing and movement of goods. Today, such types of robotics as wearable devices, manipulators, walking devices, etc. are used. In the context of this article, we do not set ourselves the task of analyzing their technical capabilities, but we should draw attention to the fact that robotic technologies are constantly being improved, which provides a new level of performance of individual and complex operations within the supply chain. At the same time, the learning opportunities incorporated in the program of robots allow logistics companies to use their capabilities with maximum efficiency, taking into account the specifics of a particular warehouse or the goods, as well as constantly reduce the number of mistakes made in the warehouse operation [23, 24].

Undoubtedly, along with the proposed innovative solutions, there are other areas of organization and improvement of supply chains. However, the presented directions to the greatest extent reflect the new reality caused by economic instability, therefore, they have real prospects for practical implementation.

\section{Results}

Highlighting the most important innovative solutions, taking into account the conditions of economic instability, actualizes the question: who and how should develop them? The correct answer to this question should be recognized as the most important result of research carried out in this area $[25,26]$. In conditions of economic instability, entrepreneurial structures that directly operate on the market for the delivery of goods need universal formalized solutions describing step by step the implementation of software products, models, algorithms.

The sphere of application of modern innovations is most often not limited to certain types of business, which is demonstrated by the practice of introducing big data, robotics or the Internet of Things. This thesis is fully consistent with our assumption of the key role of startups, since the solutions they offer are more general in nature and can be adapted to the requirements of logistics companies, or even a specific supply chain. This is what gives startups the opportunity to develop effective solutions, providing a quick response to changes caused by economic instability. The result of adaptation actions is an increase in the level of transparency in the execution of contracts, as well as solution of various technical and technological problems affecting the movement of goods, taking into account the state of access roads, road surfaces, weather conditions and other factors. 
The relationship between logistics companies and startups can be different - from concluding contracts with them to perform specific tasks to buying startups. However, the buying of such companies is not always justified. In many situations, it is preferable for all stakeholders if startups operate as independent agents, using their own methods of working. For example, startups can act as contractors whose activities can be integrated in supply chains in such operations as delivering goods in small lots or communicating with consumers, including households. This has special significance at the present time, when, in the face of the threat of the spread of the coronavirus COVID-19, it is necessary to limit human contacts.

In this context, a number of relevant areas of work of innovative startups integrated into supply chains can be considered (two of them are presented in the Table 1).

Table 1. Possibilities of minimizing contacts of people when delivering the orders to customers [27, $28]$.

\begin{tabular}{|c|c|c|c|c|}
\hline & Customer & $\begin{array}{l}\text { Scope of } \\
\text { delivery }\end{array}$ & $\begin{array}{c}\text { Problems to be } \\
\text { solved }\end{array}$ & $\begin{array}{l}\text { Necessary } \\
\text { conditions }\end{array}$ \\
\hline 1. & company & $\begin{array}{l}\text { small } \\
\text { consignmen } \\
\text { ts }\end{array}$ & $\begin{array}{lr}\text { development } & \text { of } \\
\text { technical means and } \\
\text { software r for } \\
\text { unmanned } \\
\text { transport }\end{array}$ & $\begin{array}{l}\text { a) the customer is } \\
\text { not located in a large } \\
\text { city } \\
\text { b) there is a } \\
\text { sufficient number of } \\
\text { good quality roads }\end{array}$ \\
\hline 2. & $\begin{array}{l}\text { home of a } \\
\text { specific } \\
\text { consumer }\end{array}$ & $\begin{array}{l}\text { small and } \\
\text { light goods }\end{array}$ & $\begin{array}{lr}\text { use of } & \text { unmanned } \\
\text { aerial } & \text { vehicles } \\
\text { (drones) } & \end{array}$ & $\begin{array}{l}\text { a) the customer is } \\
\text { not located in a large } \\
\text { city b) the customer } \\
\text { lives in an individual } \\
\text { house }\end{array}$ \\
\hline
\end{tabular}

Thus, the results of the study show that today, in the conditions of economic instability, new opportunities appear in the field of supply chains formation. Their implementation presupposes the widespread use of relevant innovative solutions that have real economic and managerial prospects.

\section{Discussion}

The results of the study need to be discussed from the point of view of the economic feasibility of the proposed innovative solutions and their practical implementation. Even though the proliferation of startups generally has a positive influence on reducing the cost of innovative products and know-how, new technologies involve significant development and implementation costs. In addition, the increasing complexity of innovative developments requires large material and time expenses for their commercialization and adaptation, as well as training for personnel. At the same time, the implementation of the innovative solutions presented by us will not only minimize the time of delivery goods to consumers and improve customer service, but also significantly increase labor productivity in the field of logistics operations.

Special attention here should be paid to issues related to labor productivity and the increasing role of this category during the period of economic instability. As mentioned above, the modern conditions of globalization dictate the need to increase the level of competitiveness of all national and international business entities. In this regard, the maximum gain will be received by those firms that provide the highest level of labor productivity in combination with the quality of goods and services produced. So labor productivity is considered today as the most important source of growth, not only of an individual firm, but of the entire national economy. It should be noted that in recent years, the rate of growth in labor productivity has been declining in economically developed 
countries and increasing in developing countries [29]. As for the Russian economy, the actual data illustrating the dynamics of labor productivity is presented in Table 2.

Table 2. Labor productivity indexes in the Russian economy (\% of the previous year) [30].

\begin{tabular}{|c|c|c|c|c|c|c|c|}
\hline & $\mathbf{2 0 1 2}$ & $\mathbf{2 0 1 3}$ & $\mathbf{2 0 1 4}$ & $\mathbf{2 0 1 5}$ & $\mathbf{2 0 1 6}$ & $\mathbf{2 0 1 7}$ & $\mathbf{2 0 1 8}$ \\
\hline $\begin{array}{c}\text { In general for } \\
\text { the economy }\end{array}$ & 103.8 & 102.1 & 100.8 & 98.7 & 100.1 & 102.1 & 102.8 \\
\hline $\begin{array}{c}\text { Transportation } \\
\text { and storage }\end{array}$ & 102.0 & 100.0 & 99.6 & 100.6 & 102.4 & 99.9 & 99.5 \\
\hline
\end{tabular}

Based on the relationship between innovations and labor productivity, it can be expected that the implementation of the innovative solutions presented in this article will improve the processes associated with the formation of supply chains. This will have a positive impact on the dynamics of economic indicators reflecting the functioning of related industries and the economy as a whole. As a result, this will lead to a synergistic effect neutralizing the negative processes caused by economic instability.

\section{Conclusion}

Based on the analysis, it has been proved that the following solutions will be the most promising: acceleration of all processes and operations in the delivery of goods to consumers; using advanced analytics based on data standardization; application of blockchain technologies; increased use of Internet of Things technology; improving the modeling process and giving it advanced functions; application of artificial and augmented intelligence; widespread use of robotics. Their application in practice will provide increased efficiency in the process of forming sustainable supply chains in the conditions of economic instability. Due to the emergence of a synergistic effect that integrates the innovative approaches presented in them, there will be a transition of supply chains to a higher level, ensuring the full satisfaction of the needs of all business entities - from households and business structures to the global economy as a whole.

The scientific novelty of this study lies in the fact that economic instability is presented in it as the most important factor, that positively affects the development of innovations and the implementation of innovative solutions by logistics companies in the process of improving the formation of supply chains using the latest technical and technological capabilities. This is most noticeable in the strengthening of various kinds of restrictions (including in the area of personal contacts between the seller and the buyer), which form some additional requirements for the system of relationships between business entities. This is exactly what is observed today, in the context of the COVID-19 coronavirus pandemic. Even without assessing the likelihood of the next waves of this disease, today it is necessary to search for new, alternative opportunities to meet the needs of consumers belonging to different target market segments.

Thus, there is an urgent need for the development of new and already known methods of delivery of small consignments of cargo, as well as small and light cargo. The modern practice shows us that the demand for this kind of logistics services is growing now and it will only grow. Based on the results of our research, we can recommend to focus on finding new technical opportunities for shaping supply chains that meet new conditions. Our study substantiates two interrelated approaches to solving such problems, which, among other things, also ensure the minimization of contacts between participants in supply chains, which can be both firms and individual consumers. As the technical means of delivery enhancement, such methods of work can be improved by expanding the range of tasks to be solved (for example, delivery of bulky and heavy goods or large consignments of goods) and ensuring a higher speed and quality of logistics operations. 


\section{References}

1. N. Didenko, S. Kulik, D. Skripnuk, E. Samylovskaya, 18th International Multidisciplinary Scientific GeoConferences SGEM 2018, Conference proceedings, 310 (2018) https://doi.10.5593/sgem2018/5.3/S28.001

2. R.R. Stough, New Technologies in Logistics Management. Handbook of Logistics and Supply-Chain Management (2017) https://doi.org/10.1108/9780080435930-034

3. N.V. Tumalanov, E.N. Tumalanov, V.V. Ivanov, Eurasian Journal of Analytical Chemistry 12(5b), 735-740 (2017)

4. D.I. Miropolskii et al, Economic system of the Eurasian types: problems of economic uncertainty (Saint-Petersburg, Russia, 2019)

5. J. Ghosh, European Journal of Economics and Economic Policies: Intervention 15(2), 193-207 (2018)

6. Seven years of sanctions against Russia. The main, https://www.rbc.ru/politics/16/03/2020/5bffb0f09a79470ff5378627

7. A.V. Kharlamov, T.L. Kharlamova, Sustainable Development of the Russian Economy in the Context of Global Instability. Education Excellence and Innovation Management through Vision 2020 - IBIMA, 822-830 (2019) https://yadi.sk/d/2Hacy2CZM8EPjg

8. H. Qudrat-Ullah, Innovative Solutions for Sustainable Supply Chains (Springer, Switzerland, 2020) https://doi.org/10.1007/978-3-319-94322-0

9. M.S. Golan, L.H. Jernegan, I. Linkov, Environment Systems and Decisions 40, 222-243 (2020) https://doi.org/10.1007/s10669-020-09777-w

10. D. Ivanov, Transportation Research Part E: Logistics and Transportation Review 136, 101922 (2020) https://doi.org/10.1016/j.tre.2020.101922

11. T.S. Malakhova, The transformation of the world economy in the context of global instability. The Spectrum of Opinions (Volgograd, Russia, 2019)

12. B. Asdecker, V. Felch, Journal of Modelling in Management 13(4), 840-883 (2018) https://doi.org/10.1108/JM2-03-2018-0042

13. P. Verhoeven, F. Sinn, T.T. Herden, Logistics 2(20) (2018) https://doi.org/10.3390/logistics2030020

14. H. Treiblmaier, Logistics 3(10) (2019) https://doi.org/10.3390/logistics3010010

15. T. Kharlamova, N. Grashchenko, A. Timofeeva, R. Okorokov, International Scientific Conference Digital Transformation on Manufacturing, Infrastructure and Service, Saint-Petersburg, Russia 497 (2018) https://iopscience.iop.org/issue/1757-899X/497/1

16. E.M. Frazzon, A. Albrecht, M. Pires, E. Israel, International Journal of Production Research 56, 2019-2035 (2018) https://doi.org/10.1080/00207543.2017.1355118

17. Y. Vertakova, E. Leontyev, V. Mkrtchyan, Journal of Applied Engineering Science 17(1), 74-80 (2019)

18. M. Bolsunovskaya, S. Shirokova, A. Loginova, M. Uspenskij, IOP Conference Series: Materials Science and Engineering (2019) https://doi.org/10.1088/1757899X/497/1/012024

19. A.V. Sigarev, M.V. Dubovik, E.S. Novikova, International Journal of Civil Engineering and Technology 9(10), 1131-1139 (2018)

20. S. Li, J. Yan, L. Li, IEEE International Conference on Service Operations and Logistics, and Informatics (SOLI) (2018) https://doi.org/10.1109/SOLI.2018.8476726 
21. C. Vocke, C. Constantinescu, D. Popescu, Procedia CIRP 84, 810-813 (2019) https://doi.org/10.1016/j.procir.2019.04.230

22. V. Vilken, O. Kalinina, S. Barykin, E. Zotova, IOP Conference Series: Materials Science and Engineering (2019) https://doi.org/10.1088/1757-899X/497/1/012037

23. Top 10 Supply Chain and Logistics Technology Trends in 2020 logistics technology trends, https://trademaster.ua/articles/313097

24. A. Farinelli, N.'Boscolo, E. Zanotto, E. Pagello, Robotics and Autonomous Systems 90, 34-44 (2017) https://doi.org/10.1016/j.robot.2016.08.010

25. A. Dwivedi, Innovative Solutions for Implementing Global Supply Chains in Emerging Markets (Hershey PA, USA, 2016)

26. V.S. Zharov, A.V. Kozlov, Proceedings of the 2018 International Conference 'Quality Management, Transport and Information Security, Information Technologies', IT and QM and IS, 181-184 (2018) https://doi.org/10.1109/ITMQIS.2018.8525109

27. A. Kankovskaya, O. Kalinina, I. Ilin, MATEC Web of Conferences 239, 08008 (2018) https://doi.org/10.1051/matecconf/201823908008

28. A. Dubgorn, M.N. Abdelwahab, A. Borremans, I. Zaychenko, Proceedings of the 33rd International Business Information Management Association Conference, IBIMA 2019: Education Excellence and Innovation Management through Vision 2020, 9677-9682 (2019)

29. H.H. Neve, S. Wandahl, S. Lindhard, J. Teizer, Journal of Construction Engineering and Management 9(146) (2020) https://doi.org/10.1061/\%28ASCE\%29CO.19437862.0001887

30. The efficiency of the Russian economy. Labor productivity index, https://www.gks.ru/folder/11186, last accessed 2020/07/11. 